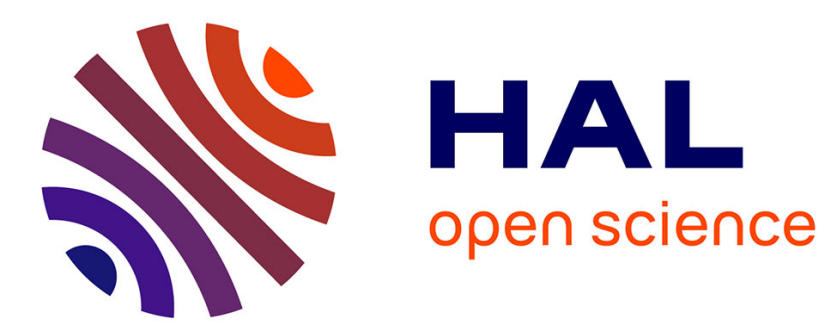

\title{
Autism from a cognitive-pragmatic perspective
}

Anne Reboul, Sabine Manificat, Nadège Foudon

\section{To cite this version:}

Anne Reboul, Sabine Manificat, Nadège Foudon. Autism from a cognitive-pragmatic perspective. Schmid, H-J. \& Geeraerts, D. Handbook of Pragmatics: Cognitive Pragmatics, Mouton-de Gruyter, pp.à définir, 2012, Handbook of Pragmatics. hal-00655404

\section{HAL Id: hal-00655404 https://hal.science/hal-00655404}

Submitted on 28 Dec 2011

HAL is a multi-disciplinary open access archive for the deposit and dissemination of scientific research documents, whether they are published or not. The documents may come from teaching and research institutions in France or abroad, or from public or private research centers.
L'archive ouverte pluridisciplinaire HAL, est destinée au dépôt et à la diffusion de documents scientifiques de niveau recherche, publiés ou non, émanant des établissements d'enseignement et de recherche français ou étrangers, des laboratoires publics ou privés. 
11. Autism from a cognitive-pragmatic perspective

Anne Reboul, Sabine Manificat and Nadège Foudon

\section{Introduction}

Autism is one of a group of three neuro-developmental disorders including, in addition to autism itself, Asperger Syndrome and a fairly heterogeneous group of patients who present some but not all of the symptoms of autism (see below, section 2.2). Asperger Syndrome and autism being the best described pathologies, notably in terms of language and language development, they will be the focus of our attention in what follows.

Autism has been described as being to pragmatics what aphasia is to syntax, i.e., a natural testing ground for pragmatic hypotheses. This is certainly true of both Asperger's Syndrome and autism, though, as will shortly be seen, autistic people are more impaired in language acquisition. The first part of the paper (section 2) will describe the pathology; the second part (section 3), the impact of the social/socio?-pragmatic deficit on language acquisition; the third part (section 4), the pragmatic deficits that remain in adulthood in Asperger and verbally autistic patients.

\section{Asperger Syndrome and autism}

\subsection{A quick historical reminder}

In 1947, Leo Kanner described a group of 11 children with the following symptoms: isolation, an obsession with routine behaviour, extraordinary memory performances, echolalia, sensibility to stimuli, a limited range of interests, normal intelligence. In 1944, Hans Asperger described a group of four children, presenting what he called an "autistic psychopathology" with the following symptoms: social isolation, linguistic and motor 
stereotypes, resistance to change, specific interests in certain objects or topics and a preserved language. Children with autism correspond to Kanner's description (with the important proviso that they arenot all normally intelligent), while children

of normal intelligence and a preserved language (as well as a more or less normal acquisition) are considered to be suffering from Asperger Syndrome. It should be noted that highfunctioning autistic adults (who have an IQ in the normal range of 70-130) and Asperger adults are very similar, the main difference between them being the differences in linguistic acquisition (see Frith 1991 and below, section 3). ${ }^{1}$

\subsection{Autism spectrum disorders: diagnostic criteria, prevalence and etiology}

Nowadays, both Kanner's and Asperger's descriptions have been largely endorsed in diagnosis handbooks, such as the DSM IV (1994), with two provisos: despite their largely common symptoms, Asperger's and autism (so-called Kanner's autism, given that it was described by Kanner), differ on the linguistic acquisition of the patients. Asperger children, despite a delay, acquire language by immersion as do typically developing children, while autistic children are not only more delayed (see below, section 3), but usually need speech therapy and about half of them remain mute. Autism is additionally fairly frequently accompanied by more or less severe learning disabilities.

Here is the complete list of diagnostic criteria of autism, as given by DSM IV: symptoms include qualitative alteration of social interactions; qualitative alteration of communication; restricted, repetitive and stereotyped behaviour, interests and activities. A second criterion is the delay or the abnormality of the following functions, which has to be evident before the child is three years old: social interactions, language necessary for social communication, symbolic or make-believe play. A final criterion is to the effect that there is no alternative explanation. 
According to Kogan et al. (2009: 2), “Autism spectrum disorders (ASD) is a group of developmental disorders comprising autistic disorders and two related but less severe disorders: Asperger's disorder and pervasive developmental disorder not otherwise specified (PDD-NOS)". The main criteria of ASD are impairments in social interaction, communication (both linguistic and nonverbal), deficient symbolic play, and repetitive and restricted patterns of behaviours and interests. The inclusion of the less severe disorders (Asperger and PDDNOS) in the autism spectrum has had the consequence of greatly increasing the prevalence of the disease from 2 to 5 in 10000 in the 1960-1980s (when the diagnosis was limited to autism) to 110 in 10000 in a 2007 USA survey (see Kogan et al. 2009), though the gender distribution has remained unchanged (with four boys to one girl). Similar though less dramatic (57 in 10000 ) increases have been reported for the UK (see Scott et al. 2002). Data for continental Europe usually concern autism and PDD-NOS rather than the whole spectrum of disorders and, as a consequence, the figure has stayed at a lower level $\left(27\right.$ in 10,000). ${ }^{2}$

The aetiology, while still not entirely clear, is heterogeneous, though there is no doubt that it is biological. Current hypotheses mainly target genetic anomalies which are linked to the $\mathrm{X}$ chromosome, but also recessive autosomal, as well as ante-, obstetric or neonatal incidents.

The heavy predominance of social deficits in the symptomatology of autism spectrum disorders does not only result in difficulties in communication, it also has consequences on the acquisition of language, and, particularly (though perhaps not exclusively, see below, 3.6.3 and 3.6.4), on lexical acquisition. In what follows, the focus will be on the two best characterized disorders, i.e., autism and Asperger syndrome.

3. The impact of the social-pragmatic deficit on language acquisition in autistic people 
As mentionedabove, the major differences between autistic and Asperger subjects have to do with learning disabilities, which are often associated with autism but not with Asperger syndrome, and with difficulties in linguistic acquisition, which are universal in autism and apparently absent from Asperger syndrome. The present section will be devoted to a description of the level of?language that both populations may achievein adulthood as a preliminary to a description of acquisition focused on autistic children. In conclusion, I will come back to the difference in linguistic acquisition between autism and Asperger syndrome and try to explain it.

\subsection{Language and ASD}

Relative to language, the subjects suffering from $\mathrm{ASD}^{3}$ can be characterised by the following schema:

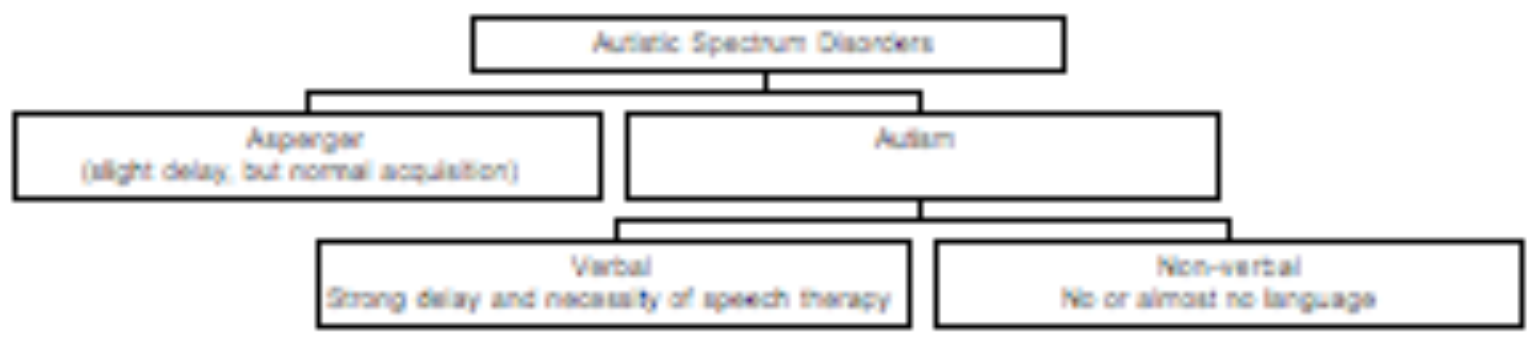

Figure 1: Language in ASD

A closer look at the chronology of acquisition between typically developing children, autistic children and Asperger children gives the results ${ }^{4}$ summed up in the following table (compiled from Bloom 2000 for typically developing children, and from Howlin 2003 for Asperger and autistic children):

Table 1: Chronology of acquisition

\begin{tabular}{|l|l|l|}
\hline Population & First words & First combinations \\
\hline Typically developing children & 11 months & 17 months \\
\hline
\end{tabular}




\begin{tabular}{|l|l|l|}
\hline Asperger children & 15 months & 26 months \\
\hline Autistic children & 38 months & 52 months \\
\hline
\end{tabular}

As is obvious, the delay in acquisition is slight in Asperger children compared to typically developing children, while it is severe in autistic children, with important consequences for schooling, for those children who might otherwise benefit from it. Indeed, the delay for first words is more important in autistic children than in children with Specific Language Impairment (Leonard 2000), who utter their first words at around 23 months of age. Additionally, an interesting factor is the gap between first words and first combinations $(\approx 2$ words), which is a mere 6 months in normally developing children, 11 months in Asperger children and 14 months in both autistic and Specific Language Impairment Children. If, as is usually assumed, first combinations signal the very beginnings of syntax, this suggestsnot only that language onset is delayed in ASD patients, but that its development is slower than in typically developing children.

Both the rather poor outcome in autistic patients (i.e., the fact that about $50 \%$ of them never acquire language, despite speech therapy) and the enormous delay in first words production seem to single them out as particularly deficient in linguistic acquisition and we will now turn to lexical acquisition in autistic children, before coming back to the difference between Asperger and autistic children in the conclusion to this section.

\subsection{Language acquisition in autistic children}

There have been very few longitudinal studies of language acquisition in autistic children, the only ones (to our knowledge) having been done by Tager-Flusberg et al. (1990) among highfunctioning American autistic children and by Foudon (2008) among French autistic children. 
We will take this second and more recent study as an example, before discussing TagerFlusberg's results below (see 3.6.3).

The longitudinal study of the French autistic children ${ }^{5}$ was conducted in the day care department of Hôpital Saint-Jean de Dieu (Lyon, France) accommodating autistic children from 3 to 12 , between 2005 and $2008 .{ }^{6}$ We followed three groups of autistic children, assembled to correspond to three rough stages of linguistic acquisition, based on the Mean Length of Utterance (MLU) ${ }^{7}$ of each child at the beginning of the study, for three years:

- First words (MLU = 1);

- First combinations (MLU $\geq 2$ );

- First sentences (MLU > 2).

The idea was thus to cover the whole spectrum of language acquisition, because, given the slow development of language in autistic children, one cannot be sure that an autistic child at the first word stage, even if he ${ }^{8}$ turns out to be verbal later on, will have progressed to the final stage three years later. Children were recorded every three months (excepting the summer period), that is three times a year in three situations (work, play, meal) in the day care department they attended. The corpora were transcribed according to the prescriptions of CHILDES. Criteria for inclusion were a diagnosis of autism in accordance withthe recommendations of DSM IV and an absence of auditory impairment. IQ level was not a criterion for two reasons: it is very difficult to assess in autistic children with a low linguistic development and in contrast with Tager-Flusberg's 1990 study, we wanted to investigate language acquisition in autistic children regardless of their intellectual abilities. Thus, the children selected, apart from the obvious criteria indicated above, merely had to show an MLU corresponding to one of the three stages of language acquisition indicated above to be included in the study.

The resulting group of children was composed as follows: 
- The first words group consistedof two boys (3.3 and 3.5 years at the beginning of the study), and a girl (2.8 years);

- The first combinations group also consisted of two boys (4.5 and 5.5 years), and a girl (7. 9 years);

- the first sentences group again consisted of two boys (8.11 and 7.8 years), and a girl (5). ${ }^{9}$

One child in the first group did not utter a single word in any recording session after the first one, and we therefore did not include him in our analyses. We will quickly present the preliminary analyses which have been carried out on the corpora and which give a good idea of acquisition in autistic children.

Unsurprisingly, given the heterogeneous profile of autistic children in terms of language (see also Kjelgaard and Tager-Flusberg 2001; and below 3.6.3), the progression of the children in our sample was highly diverse. We were able to separate the children into three groups depending their linguistic development: two who do not progress at all, three who do progress, but only slightly, two who have progressed fairly well, leaving aside one, whose progress curve was so chaotic as to defy description. It should be noted that the progression is very slow, by comparison with typically developing children, ${ }^{10}$ who, in six months, will progress from one word utterances to four words or more, leaving the autistic children far behind. Thusautistic children are, indeed, not only delayed in terms of language onset, they also progress extremely slowly relative to typically developing children.

We complemented the MLU by two other measures: we plotted the repartition of syntactic categories in the final sessions of our two best developing autistic children and compared it to that of TD children with the same MLU. The results were interesting in that in TD children with $\mathrm{MLU}=3$, words are distributed, with an astonishing regularity, in $30 \%$ verbs, $10 \%$ nouns (including proper names) and $60 \%$ of function words, while one ASD child's words are distributed in $35 \%$ verbs, $15 \%$ nouns and $50 \%$ of function words and the 
other's are distributed in 30\% verbs, $20 \%$ nouns, and 50\% function words. ${ }^{11}$ In other words, in those two children who have progressed rather well, the syntactic distribution of words, though it is near to TD children's, remains different from it.

Very much the same conclusion can be drawn from a last measure, that of agrammaticalities: we counted the number of omitted pronouns and determiners, non conjugated verbs, missing prepositions and faulty agreements. The number of such agrammaticalities was very high in the first sessions for TD children, but diminished fairly rapidly and, indeed, completely disappeared in the last sessions. In autistic children, the results were more heterogeneous, but, again, in those two who reached $M L U=3$, the number of agrammaticalities, though it diminished strongly, still remained at around $2 \%$.

Thus, on the whole, the general picture that can be drawn from that longitudinal study is that linguistic acquisition in autistic children is fairly heterogeneous and that, even in those autistic children who do reach the sentence level (and who, hopefully, will presumably progress well over the MLU $=3$ stage in the future), language still remains slightly different from that of TD children at the same level.

Before we turn to an explanation of why this should be so, let us now quickly outline a currently well-accepted model of language acquisition.

\subsection{The Emerging Coalition Model of language acquisition}

A child acquiring language has to solve three different problems:

- Isolating words in the flux of speech;

- Isolating objects and events in the environment (categorisation);

- Mapping words and objects and events.

Hirsh-Pasek and Golinkoff (see, e.g., Hirsh-Pasek and Golinkoff 1996, 2006) have proposed a model of language acquisition, the emerging coalition model, that has the 
advantage of taking a strong developmental stance towards lexical acquisition. At a first stage (roughly concomitant with first words: 9-18 months), the child will mainly rely on spatiotemporal coincidence between a word and the corresponding and perceptually salient object or event. This first period, strongly relying on association, is followed, between roughly 18 to 24 months, by a period during which the child begins to use socio-pragmatic cues such as gaze direction, intention, etc. Finally, from 24 months on, the child adds to his repertoire morpho-syntactic cues, as syntax kicks in, allowing him/her, e.g., to distinguish different syntactic categories which frequently map either onto objects (e.g., names, adjectives) or onto actions (verbs).

A first advantage of the model is its taking into account the development of nonlinguistic abilities in the first two years. This is especially relevant in autism, which is considered as a developmental pathology because development in autism is heterochronological or disharmonious. In other words, the retarded, absent or faulty development of an ability in autistic children may block or retard the development of normal linguistic acquisition.

There are reasons to think that autistic children have difficulties with all three problems. Regarding the individuation of words, recent works (Saffran, Aslin, and Newport 1996; Saffran, Newport, and Aslin 1996; Aslin, Saffran, and Newport 1998) have highlighted abilities for statistic processing of auditory stimuli in infants and have proposed that these abilities are the basis for word individuation, through the detection of acoustic regularities in linguistic stimuli. This, however, supposes that children are able to filter out what is not linguistic in the auditory environment, an ability which seems very precocious in TD infants (see, e.g., Winkler et al. 2003), who preferentially orient toward human voices (and particularly toward their mothers' voices), but which seem absent in children with autism (see Klin 1991 and Ceponiene et al. 2003). Regarding the individuation of objects and events, 
autistic patients seem to have specificities in categorical perception (see Soulières et al. 2006) and to be more dependent on prototypicality in concepts than are normally developing controls (see Gastbeg 1999). Finally, the mapping between words and objects and events is usually dependent in normally developing children on so-called socio-pragmatic cues (see e.g. Bloom 2000; Tomasello 2005, 2008). Given the strong deficits in social abilities in autistic children, there is little reason to be optimistic regarding their performances in solving this specific problem.

These difficulties in lexical acquisition allow an explanation of the gap between first words and first combinations in both autism and Asperger's Syndrome. Indeed, a fairly recent hypothesis (Hirsh-Pasek and Golinkoff 1996) introduces the notion of a critical threshold in terms of a vocabulary size under which syntax does not develop. This hypothesis, which has been empirically validated, places the threshold at between 250 and 300 words in the child's vocabulary to trigger the development of syntax. What this suggests relative to the longer gap between first words and first combinations in both Asperger and autistic children is that their main problem may be in lexical acquisition, which would proceed at a slower pace than in normally developing children, thus explaining why they are so late in producing first combinations and first sentences. ${ }^{12}$ Let us now turn to why vocabulary should be acquired later and more slowly in autistic and Asperger children.

\subsection{Socio-pragmatic abilities}

On the hypothesis just described, syntax appears only when a certain threshold is reached in terms of vocabulary size. We will mainly concentrate here on socio-pragmatic abilities.

What socio-pragmatic cues do in lexical acquisition is help the child match the words heard to the objects or events isolated in the world. This enables her to learn words which she picks up in the adults' utterances even when they are not directly addressed to her. The onset 
of socio-pragmatic abilities at around 18 months coincides with the so-called word spurt, a dramatic increase in lexical acquisition.

These socio-pragmatic abilities are the ability to cooperate in a common activity with an adult (so-called shared intentionality, see Tomasello et al. 2005; Tomasello 2008), the ability to engage in shared attention (see, e.g., Baron-Cohen 1995), and, to a lesser degree, the ability to engage in joint attention (Moore and Dunham 1995; Eilan et al. 2005). The most basic and precocious one is presumably ${ }^{13}$ joint attention, which begins at around 9 months and seems fully functional by 12 months. It consists in the fact that when the adult (parent or caretaker) turns his/her head to look at an object or event, the baby will automatically turn itshead in the same direction. The final stage (by 12 months) is reached when the child will follow another's gaze to an object behind a visual obstacle. This automatic behaviour does not seem to exist in autistic children at the same age (indeed, it could be one early diagnostic sign of autism, see, e.g. Reznik et al. 2007; Bryson et al. 2007), though it may develop much later on. This is not due to an incapacity to follow glance as such, as was shown in an experimental study by Leekham et al. (1993), where autistic children performed at the same level as typically developing children in a task where children were explicitly asked to say or show what an actor was looking at. Rather, it seems that, although they are able to follow glance if explicitly asked to do so, autistic children do not do it spontaneously or, indeed, automatically.

The next ability, which can be seen as a development from joint attention, is shared attention that is fully functional in typically developing children by 18 months (see BaronCohen 1995). Shared attention is the behaviour that the child manifests, when it not only follows an adult's gaze but alternates its own gaze between the object and the adult's face to check whether they are indeed sharing an attentional state toward the same object. Shared attention seems an important step toward so-called shared intentionality. In the description of 
it/As described by Tomasello and his colleagues (see Tomasello et al. 2005; Tomasello 2008), shared intentionality entails shared attention, but, in addition, according to the authors it entails the ability to represent the other's intentions and one's own intentions as part of a recursive shared intention (e.g., I intend that she intends that I intend... that we open this box). Shared intentionality behaviour is taken to be important in language acquisition in that it makes it simpler to converge on a common ground, i.e., a set of pieces of information shared between interlocutors, of which each knows that the other knows it.

The potential contribution of shared intentionality to lexical acquisition seems pretty obvious: it facilitates inferences as to what the adult may be talking about. However, its application seems restricted, given that it presupposes that the child and the adult are doing something together. By contrast, it is now well known that typically developing children can learn words (at least $30 \%$ of newly acquired words) from utterances that are not addressed to them and that are not necessarily part of a joint activity (see Bloom 2000). This is where the attentional abilities, both joint attention and shared attention, come into play, allowing the child to identify what the adult is talking about on the basis of what he/she is looking at, even when his/her utterances are addressed to a third party. Autistic children are deficient, not so much in the ability to compute gaze direction, but in the motivation for using that ability. Thus they do not (reg) develop (or develop only much later) joint attention, i.e., spontaneous head turning to follow another's gaze. Given that shared attention is a development of joint attention and presumably rests on the same motivation, it can hardly come as a surprise that they do not develop shared attention either.

\subsection{Socio-pragmatic deficits in autism: the motivation hypothesis}

This seems to place motivation at the centre of the social deficits in autism, which would strengthen Tomasello's (2008) position regarding the species-specific motivation for 
cooperation. His argument in defence of this hypothesis is based on TD children's tendency to point, which appears at around 12 months and remains very strong in the first few years, before being largely superseded by language. While proto-imperative gestures (gestures produced in the intention of obtaining something from the adult) do not manifest any specific social ability and certainly no motivation for sharing or cooperation, proto-declarative gestures, which appear slightly later, do manifest it (see Bates, Camaioni, and Volterra 1975). This is because in proto-imperatives, the other can be used as a (non-intentional) tool to satisfy a wish or an intention of the child, while in proto-declaratives, the only reward is the very sharing of the attitude with the (intentional) adult. Autistic children use proto-imperative pointing, but only rarely point in a proto-declarative way (Sigman and Kasari 1995; Tomasello et al. 2005; Tomasello 2008). Thus what is crucial may be the motivation for sharing which underlies both behaviours.

Being deprived of the abilities which allow typically developing children to keep track of simple epistemic states of adults (such as attention) can only hinder lexical acquisition by restricting its mechanisms to association based on coincidence between salient word and salient object, which is in part what speech therapies rely on for autistic children. However, this means that, in contrast to normally developing children, the only times when autistic children will learn new words are precisely when they are specifically taught them either by their parents or during speech therapy and specialized tuition.

An important argument relative to the motivation hypothesis is echolalia. Echolalia, which can be immediate or delayed, is defined as rote and literal repetition of utterances, which are reproduced without modification. It was identified by Kanner (1947) as fairly frequent in autism. Though echolalia was first seen as an obstacle to language acquisition, pioneer studies (for a review, see Schuler and Prizant 1985) have shown, first, that in fact echolalia is not a monolithic phenomenon, second, that children with echolalia have a better 
long range prognosis for language acquisition, and, third, that at least some kinds of echolalia, though inappropriate in as much as they may not be readily understandable by addressees, do manifest the will, but not the linguistic abilities to communicate. Thus, though some children with autism may entirely lack the motivation for social contact and social communication, this is not as general as has often been thought.

If, as proposed above, the deficits in socio-pragmatic abilities hinder lexical acquisition in autism, then the often observed regression and the strong delay in language acquisition which are characteristic of autism are readily explained. Indeed, parents of autistic children often report a normal onset of single word production at the end of the first year, followed by a regression after 18 months (see Rapin and Dunn 1997). Regression in language acquisition at around 18 months corresponds to the absence in autistic children of the sociopragmatic processes which should come in at that age and strongly increase the rate of lexical acquisition, while the general delay can be explained by the rather limited inputs which autistic children are able to take into account as compared with typically developing children. This delay and the general slowness of lexical acquisition explains, in its turn, the late syntactic development manifested by those children who finally acquire language and, as we shall shortly see, may explain some linguistic specificities and difficulties of verbal autistic patients.

\subsection{The differences and similarities between autism and Asperger Syndrome}

\subsubsection{Questions}

Given what is shared between autistic and Asperger Syndrome patients, i.e., all social deficits, and what is not, i.e., the strong delay and specificity of language acquisition in autism as opposed to Asperger Syndrome, how could one claim that the deficit in language acquisition which is specific to autism can be explained by the socio-pragmatic deficits which are 
common to both autism and Asperger Syndrome? This is of course not only a question, but a potential objection to the theory outlined above. An additional question is why some autistic children never acquire language (in the strong sense that they remain mute), while others do.

Let us begin with the second question. It is usually considered that language acquisition and intellectual abilities are dissociated in that an intellectually deficient child can acquire language normally, which seems to indicate that linguistic acquisition can proceed despite severe intellectual disabilities. This has been shown recently by Musolino, Chunyo, and Landau (in press) who investigated syntactic and structural (syntactically-linked) semantic abilities in children with Williams' Syndrome ${ }^{14}$ and found them to be identical with normally developing children, in contradiction to other studies (see, e.g., Karmiloff-Smith et al. 1997), that found them linguistically disabled. It may nevertheless be the case that the most severe cases of linguistic disabilities in autism also are those associated with severe intellectual disabilities, which, given the social deficits in autism, cannot be compensated through socio-pragmatics abilities, as it may be the case with other intellectual disabilities such as Williams' Syndrome or trisomy.

3.6.2. Are Asperger Syndrome and autistic adults really so different with regard to linguistic abilities?

Turning back to the first question, i.e., the apparent discrepancy between autism and Asperger Syndrome, it is not clear that, in adulthood, the discrepancy is as strong as it seems. Indeed, in a study, Howlin (2003) investigated two groups of adults (over 18 years), the first highfunctioning autistic patients, the second Asperger patients. She used a battery of standardized vocabulary tests, initially devised to test linguistic abilities in typically developing children of school age (British Picture Vocabulary Scale and Expressive One Word Picture Vocabulary). She found out that the differences between the two groups were slight. Even more surprising 
was the fact that more than half of the participants in each group were far below ceiling. What this suggests is that, despite the important delay in language acquisition in autistic children, the differences between the two pathologies (in those autistic patients who are not intellectually impaired) tend to level out in later age. What is more relevant here is that this suggests that, despite an apparently normal linguistic acquisition, Asperger children may in fact be limited in their linguistic development, and, more specifically, given that Howlin's study is focused on vocabulary assessments, in lexical development. In other words, though less impaired in early linguistic acquisition, they may nervertheless be impaired to a level comparable with that of autistic children in later years. The slight discrepancy between the two groups might then be entirely explained through the delay in early acquisition in the autistic group. What remains mysterious, however, is why there is this early difference in linguistic acquisition.

A first and perhaps obvious explanation may well be that, Asperger Syndrome patients being usually diagnosed much later than autistic patients, ${ }^{15}$ their social deficits in infancy are not well described and may be much less acute than those of autistic children. Thus, they might be less impaired, for instance, in joint attention. There are however other possibilities.

\subsubsection{Is autism sometimes associated with specific language impairment?}

Another possibility is that, in addition to their social deficits, children with autism have a specific language impairment of some kind (in other words, there is in autism a comorbidity between the social deficits and a specific language impairment, while Asperger children would only be impaired in social cognition and behaviour). This second possibility has some evidence in its favour.

As said above, Tager-Flusberg et al. (1990) conducted a longitudinal study on American autistic children. Their conclusions at the time were that linguistic acquisition in 
autistic children, despite the delays and the relative slowness of the process, followed the same acquisitional steps as that of typically developing children in terms of syntactic milestones. This seemed to exclude any kind of specific language impairment. However, in a later study, Kjelgaard and Tager-Flusberg (2001) tested a group of 89 children with autism (aged 4 to 14) using standardized linguistic tasks. They got the usual result of highly heterogeneous linguistic development and further tested the less able group with a test which has been considered as an acid test for specific language impairment, i.e., non-word repetition (see Tager-Flusberg and Cooper 1999). These less linguistically able autistic children, as do SLI children, fail tests of non-word repetition, which suggests that they may indeed evidence a comorbidity between the social deficits typical of autism and SLI.

The results of these two studies may appear to be contradictory, though this is less obvious on reflection, given the rather high performance of the group of children in the initial longitudinal study and given that the "autism + SLI" hypothesis is specifically directed toward the less able group of autistic children. However, other hypotheses are possible.

\subsubsection{The critical period hypothesis}

A recent review (see Durleman and Zufferey 2009) both documents limits in syntactic performance in autistic patients and criticises the hypothesis that poor linguistic performance is due to a comorbidity with specific language impairments. The authors propose that the limited syntactic abilities in autistic patients is due to the delayed acquisition which has the consequence that syntax has only a restricted time in which to develop before the end of the critical period ${ }^{16}$ and, indeed, stops developing before it reaches the standard level, hence the persisting syntactic limitations, even in verbal autistic subjects, in adulthood.

OnAccording to? that view, autistic patients will be more or less syntactically impaired, depending on their initial delay and on the rate at which their vocabulary develops, 
until it reaches the critical threshold at which syntax is triggered. There is unfortunately no study comparing Asperger and high functioning autistic adults' syntactic performances: a discrepancy between their performances might be related to the difference between the mean dates of syntax onset in the two groups (26 months in Asperger as contrasted with 52 months in autistic children). This could bolster the critical period hypothesis, which, as just outlined, is entirely compatible with the socio-pragmatic hypothesis regarding lexical acquisition.

\subsection{Summary}

/To sum up, the social deficits in autism may go a long way to explain both the extreme delay in language acquisition and the remaining deficits in adulthood, by their effects on lexical acquisition, with the consequence that the critical threshold at which syntax is triggered occurs so late that syntactic acquisition proper has a limited period during which it can develop. This itself explains the remaining syntactic limitations of autistic patients in adulthood, as well as their deficits in theory of mind, with consequences on pragmatics, which are a strong characteristic of autistic communication in adulthood.

\section{Pragmatic deficits in verbally autistic patients}

Although, as just noted, recent studies have listed lexical deficits in both Asperger and autistic verbal adults and syntactic deficits in autistic verbal patients, former studies mainly reported an intact language but strongly impaired communication abilities (e.g., Frith 1990). These encompass difficulties with non-literal communication (tropes, metaphor, irony, indirect speech acts, incomplete instructions relying on common knowledge, implicatures, etc.), with politeness, turn-taking in conversation as well as in subject maintenance or, equally, with persistence on subjects which are inappropriate in the context (rude or boring to conversation partners who do not share the Asperger or autistic speaker's specific interests ${ }^{17}$ ). Pragmatic 
and discourse difficulties meet in that both may be due to some deficit in theory of mind, as we will now see.

\subsection{Theory of mind}

Theory of mind is the (probably species-specific) ability which allows humans to predict and explain others' behaviours through the mental states (beliefs, desires, intentions, emotions, etc.) which they attribute to them. A simple example is when one sees someone else going to the refrigerator, opening it, taking out a water bottle, filling a glass and drinking it. If one is a

typically developing human, by age 5 at the latest, one will be able to explain that behaviour through the fact that the agent was thirsty and believed that there was water in the refrigerator. On the prediction side, if one knows that an agent is thirsty and believes that there is water in the refrigerator, one can predict that the agent will go to the refrigerator, take the water bottle out, etc.

There are a few different theories on what theory of mind is. A first family/set? of views is to the effect that theory of mind actually is a theory (see, e.g., Fodor 1992). This first family of views can be subdivided according to whether its proponents take theory of mind to be both modular and innate (as Fodor does) or to be modular, but not innate beyond the postulation of cognitive biases (see, e.g., Gopnik and Meltzoff 1993).

A second family of views defends the notion that theory of mind is, in fact, not at all a theory, but mainly operates through simulation. The simulator puts him/herself in the shoes of the person whose behaviour they want to predict, using their own cognitive processes "offline", accessing the result through introspection and transferring that result to the agent's actions. The notion of simulation has received partial support from the discovery of mirror neurons (i.e., neurons which fire both on performing an action and on seeing someone else performing the same action: see Rizzolatti and Sinigaglia 2007) and has been developed 
accordingly (see Goldman 2006). Let us now shortly outline the involvement of theory of mind in pragmatic processing.

\subsection{The contribution of theory of mind to pragmatic processing}

One can see the early history of pragmatics (speech act theory, see Austin 1962; Searle 1969) as a continuous endeavour to integrate language, and particularly language use, in action, i.e. to consider language use as a behaviour on a par with any other kind of public behaviour. What this means, basically, is that language use, i.e., the production of utterances, works at least in part like any kind of intentional behaviour (and notably rests on a mixture of beliefs and intentions) and is thus susceptible to the interpretive processes dedicated to the explanation and prediction of behaviour in general. In other words, the interpretation of utterances, just as the interpretation of actions in general, involves theory of mind. This view was explicitly articulated by Grice in the sixties and seventies (though not in these terms; see Grice 1989), who described conversation as a cooperative endeavour and defined meaning as depending on the speaker's intentions and communicative success as depending on the hearer's/listener's? recovery of the speaker's intentions. The final step was reached in the eighties with Relevance Theory (see Sperber and Wilson 1995), which introduced the notion of ostensive communication (i.e., communication which advertises itself as such) and argued that utterances came with a guarantee of optimal relevance. Relevance was defined, in economic terms, as a balance between cognitive processing efforts and cognitive (roughly informational) effects. Thus a competent speaker would choose his utterance on the basis of what (epistemic) mental states he/she attributed to their hearer/listener. In other words, from its speech acts beginnings to its latest cognitive developments, pragmatics is rife with implicit or explicit appeals to mental states attribution, both in utterance production and in utterance interpretation. 
A strong prediction of pragmatics is thus that someone who is impaired in terms of theory of mind will also be impaired in linguistic communication, and ASD patients seem to strongly vindicate this view, as we will shortly see, after discussing theory of mind in autism.

\subsection{Theory of mind in ASD}

The notion of theory of mind was introduced in a famous paper by Premack and Woodruff (1978, in Behavioral and Brain Sciences), in which they asked whether the chimpanzee had a theory of mind. In the peer comments following the paper, a few philosophers, prominent among whom was Dennett (1978), proposed that a fair test of theory of mind would have to rely on false belief attribution. The resulting test was based on a story in which a first character places an object in a given location, leaves the room and, during its absence, a second character takes the object and places it into another location; then, the first character comes back (Wimmer and Perner 1983). The children are asked first (control question) where the object is now, and second (test question) where the first character will look for it. Though the correct answer to the first question is based on the present situation and does not tap theory of mind, the correct answer to the second question implies attributing a false belief to the character and, hence, implies theory of mind. TD children pass false belief test during their fifth year (by 5 years at the latest) (for a review see Wellmann, Cross, and Watson 2001). In autism, however, results have found that ASD patients are impaired in theory of mind (see, e.g. Baron-Cohen, Leslie, and Frith 1985).. Though the hypothesis of a central theory of mind deficit in autism (first proposed, but then rejected, by Uta Frith: see Frith 1990) has by now been abandoned as failing to account for all cognitive peculiarities in autism (notably for both preserved "islands" of ability and for perceptual specificities), there is no doubt that theory of mind is usually deficient in ASD patients. Some Asperger Syndrome and high functioning autistic patients do pass false belief tasks, but it is not clear 
whether they do so through the same processes as typically developing subjects or through compensatory strategies, such as those often described by???meaning or high functioning ASD people themselves for dealing with social situations in general (see e.g., Grandin 1995; Williams 1992): in other words, they rely on explicit analyses of those situations rather than on the fairly quick, automatic processing which is used by TD people. Though this may lead them to pass false belief tasks, such an analytic strategy would be powerless to compensate for the fairly quick processes implicated in linguistic communication.

\subsection{Pragmatic difficulties per se}

One difficulty in assessing pragmatic difficulties in ASD patients is to disentangle the respective contributions of language deficits from pragmatic deficits per se. The most common strategies are either selecting ASD patients with a normal VIQ (verbal IQ), and comparing them with TD subjects, or to comparing ASD patients with both specific language impairment (SLI) patients and TD subjects. The idea behind the first strategy is to avoid the potential language deficit, while the idea behind the second strategy is to check the potential implication of a language deficit in the task by using a specifically language disabled population (the SLI patients).

One area of potential interest here is disambiguation, because it entails both linguistic competence and the ability to use and process contextual information. Norbury (2005) has investigated these abilities in four populations: patients with ASD and language impairment (ALI), patients with ASD and without language impairment (ASO), patients with language impairment (LI), and typically developing children (TD). The participants were 9- to 17-yearolds. The children were asked to judge whether an image matched the meaning of an ambiguous word, where that meaning could be either the dominant or the subordinate meaning. The results were interesting in that the two groups with language impairments had 
difficulties in using context for disambiguation, while the two groups with normal VIQ did not. In other words, the relevant factor was not the autism, but the linguistic abilities of the subject. The poor performance of the two language-impaired groups might be explained by the poor semantic knowledge of the verbs used to disambiguate the target words. This shows the importance of disentangling the linguistic deficits from the pragmatic deficits in the poor performance of ASD patients in pragmatic tasks.

As said above, high functioning autistic and Asperger patients are impaired in the interpretation of utterances, from clearly figurative ones (metaphor and irony) to clearly literal but incomplete ones. Let us begin with a few examples:

(1) Can you pass the salt?

(2) Put the chicken in the oven at eleven, please.

(3) Has the cat got your tongue?

ASD patients have problems with all of the above sentences. Numerous studies (e.g., Frith 1990; Atwood 1998) have reported that an indirect request such as (1) will usually get the answer "yes", without the child or adult passing the salt. There are a lot of anecdotes from parents of ASD children to the effect that even teenagers or adults will indeed, in response to an order such as (2), put the chicken in the oven, but will not turn it on. Finally, an idiom such as (3) will get a bewildered, if not fearful, reaction.

What happens with all these examples is that there is a gap between the literal linguistic interpretation of the utterance and the interpretation the speaker intended to get across. In (1), the linguistic interpretation is a question, while the utterance is intended as a request; in (2), the linguistic interpretation is that the addressee should put the chicken in the oven, but the speaker's intention was that the chicken should be put in an oven which is switched on; finally, by the idiom in (3) the speaker intends to ask the addressee why he does not talk. Thus, what seems difficult for ASD patients is the discrepancy between the 
interpretation based on the linguistic code, which the patients can access, and the interpretation intended by the speaker, which the patients not only seem to have difficulty accessing, but of which they are clearly not aware. In other words, it seems that ASD patients believe linguistic communication to be a mere matter of encoding and decoding, when it is in fact, additionally, a matter of inferential interpretation. It is relevant that being aware of the gap supposes some degree of theory of mind, ${ }^{18}$ in a way that it is reminiscent of the false belief task: just as, in the false belief task, the incorrect answer to the test question rests on the situation (i.e., describes the actual location of the object) and neglects the first character's state of mind, in utterance interpretation, ASD patients take the strictly linguistic interpretation to be the right one, ignoring the fact that the speaker's intention may be different in one way or another. It is, indeed, one of the things reported by high- functioning ASD people (Grandin 1995; Williams 1988), that they are bewildered by the very fact that people may intend to communicate something which is different from what they said (in the non Gricean sense).

From this point of view, it is hardly surprising that ASD people find metaphor and irony difficult and this has been specifically investigated by Happé (1993) following Relevance Theory's analysis of these tropes. Very roughly, Relevance Theory links metaphor interpretation to first-order theory of mind (such as that tested in false belief tasks, e.g., Mary believes that $p$ ), while irony, considered as echoic, is supposed to necessitate second-order theory of mind (e.g., John intends Mary to believe that p). Happé contrasted three types of utterances: similes (supposed to be literal and thus interpretable without any theory of mind), metaphors (necessitating a first-order theory of mind) and ironies (necessitating a secondorder theory of mind). She tested both verbally autistic children (aged 9 to 26 years) and children with mild intellectual disabilities (aged 12 to 36 years) both on theory of mind first and second-order tasks and on understanding of all three types of sentences. The results were 
in line with Relevance Theory's predictions, i.e., similes were understood by all participants, metaphors were understood by participants with at least a first-order theory of Mmind, while irony was understood only by participants with second-order theory of mind. An additional finding of the study was that the verbal age needed for autistic patients to understand metaphor and irony was much higher than that needed for the controls who were not as delayed or impaired in terms of theory of mind. What this dissociation between language and pragmatic interpretation shows is of course not that one does not need language to interpret metaphor and irony, but rather that language is not enough. Thus for those ASD patients who do not have first-level theory of mind (the majority of them), linguistic communication will be problematical? in that the very pragmatic interpretation of even simple utterances will be impaired.

Pexman and colleagues (2011) have focused on irony and tested three groups of 8year-olds: patients with high-functioning ASD (with a verbal ability of at least 5 years of age), and two groups of typically developing children, one matched in chronological age, the other matched in verbal age. To facilitate the task, children were asked to judge the speaker's belief, the speaker's humour and the speaker's intent (critical or complimentary), by respectively answering a question, choosing a face in a face scales (from very funny to very serious) and a stuffed toy (either a soft smiling duck, or sharp-teethed shark). In this less demanding task (as the responses were non-verbal and forced-choice), children with ASD performed as did TD children in judging speaker's belief and speaker's intent, but were less good at recognizing speaker's humour. Further analyses of response time and eye gaze suggested, however, that the ASD group did not use the same process as did the control groups and the hypothesis is that they used an explicit, rule-based rather than a simulative strategy.

The difficulty the children with ASD had with spotting the humour in Pexman et al.'s study echoes a general difficulty that autistic patients seem to have with humour in general. 
This was addressed in a paper by Emerich and colleagues (2003), who compared two groups of 11- to 17-year-olds, one high-functioning ASD group, and one TD group, on their ability to choose the right ending to a sequence of cartoons or to a joke. Though the two groups performed similarly on the cartoon task, the ASD group performed significantly less successfullythan controls on the more abstract joke tasks. The ability to appreciate humour depends both on the ability to process context and identify the underlying 'incongruity', but it also depends on the ability to identify the speaker's intention.

Still another area of interest here lies in the ability to make context-based inferences. This has been investigated in the interpretation of questions by Loukusa et al. (2007) in a comparison of three groups of children: 7- to 9-year-olds and 10- to 12-year-olds highfunctioning ASD patients, and a control group of 7- to 9-year-old TD children. The questions used in the experiment differed in how much their interpretation relied on contextual inference: reference assignment (Who is running on the road?); enrichment (What time might it be?); basic implicature (Why is the boy holding a book over his head?); feeling (How does the boy feel?); routine (What does the mother mean?). In addition, the children were asked to justify their answers. The results indicated that the ASD group had difficulties with the contextually demanding questions, though the older age group did better than the younger. While all groups answered the reference assignment questions easily, the younger ASD group had difficulties with enrichment questions, and both ASD groups had difficulties with basic implicature, routine and feeling questions.

Implicatures are of course the paradigmatic pragmatic process, and they were first investigated by Surian and colleagues (1996), who compared high-functioning autistic patients, SLI patients and typically developing controls (all groups 10- to 12-year-olds). The children were presented with two dolls who answered a question posed by a third doll, either in keeping with Gricean maxims or not, and asked to point out the doll who 'said something 
silly'. All the controls, the SLI patients and three (out of eight) ASD patients performed significantly above chance. The five remaining patients with high-functioning autism failed the task. There was a straightforward association between success in the implicature task and success in the false belief task in autistic patients.

Rather different results have been found regarding scalar implicatures. Scalar implicatures arise when the choice of a weaker term implicates the negation of a stronger term (i.e. The orchestra played some Beethoven sonata implicates The orchestra did not play all Beethoven sonata). Pijnacker and colleagues (2009) compared high-functioning autistic patients, Asperger's syndrome and matched controls (adults of 26-27 years of age). They used two scalar triggers, some and or and asked subjects to judge whether statements were true or false (e.g. All sparrows are birds; Some sparrows are birds; All birds are sparrows; Some birds are sparrows). All participants derived the scalar implicature quite frequently and there was no significant difference between the groups. Further analyses revealed that lower verbal IQ in the autistic group was associated with less pragmatic responses. Again, the autistic group was significantly slower in answering than the other two groups. This rather unexpected result could be explained by the fact that the demands of scalar implicatures are rather less strenuous than those of other pragmatic phenomena, asking only for first-order theory of mind. A second reason might be that both groups of patients had average to high IQ and were adults and so had had time to develop strategies different from those of the control group.

Finally, a further study by Chevallier and colleagues (2010) investigated the role of prosody in the derivation of scalar implicature in high-functioning autistic adolescents. The logic was that stress on the implicature trigger would facilitate the derivation of the implicature in typically developing controls, but not in the patient group, because of the wellknown difficulties of autistic patients with prosody. Patients were presented with two pictures 
and a statement and asked to judge whether the statement is true or false (i.e. a picture of a window, a picture of a monkey and the statement There is a window or/OR a monkey). Contrary to expectations, the two groups did not differ in their abilities to make the scalar implicature. This suggests that individuals in the high-functioning range of ASD do have some pragmatic (including prosodic) competence. It should be noted, however, that these people, despite their good performance in tests, can still be handicapped in everyday conversation, which is more taxing than experimental setups.

\subsection{Discourse deficits in autism}

A first investigation of discourse deficits in autism was made by Eales (1993), who compared a group of patients with a childhood diagnosis of autism to a group of patients with a childhood diagnosis of receptive language disorder (both groups adults: 23- to 25-year-olds). The study was done on a corpus recorded while the participants were interviewed using the ADOS (Autism Diagnostic Observation Schedule: a standardized questionnaire to diagnose autism). A range of factors was investigated: the rate of inappropriate utterances; the rate of empty turns; the ratio of initiations; as well as sub-categories of these. The autistic group was much worse as far as stereotyped language use and impairment of communicative intention (two sub-types of inappropriate utterances) were concerned. These were associated with greater social impairment in ADOS.

In a recent paper, Hale and Tager-Flusberg (2005) investigated discourse deficits in autism by the analysis of corpora recorded in child-mother interaction and coding for noncontingent utterances (i.e., utterances not relevant to the prior speaker's topic). The study included 57 verbal children with autism (age 4 to 13) and aimed at correlating their discourse difficulties to their score in a standardised test for autism, ADOS. This is in fact what they found, i.e., scores in noncontigent discourse and scores in ADOS were significantly related. 
More tellingly, "impairment in the domain of communication, ${ }^{19}$ but not in social interaction, was significantly related to noncontigent discourse, independent of more general language skills" (Hale and Tager-Flusberg 2005: 523).

This is quite reminiscent of Happé's results regarding the interpretation of metaphor and irony, given that, once again, the major factor does not seem to be language as such, but rather communication and, here, the authors suggest that discourse deficits may be related to theory of mind rather than to social abilities per se, though it should be noted that the children were not specifically tested for theory of mind.

Finally, the narrative abilities of autistic patients have been investigated by Colle and colleagues (2008), who compared a group of adults with either high-functioning autism or Asperger syndrome and matched controls (both age 27 years of age) on a range of factors: anaphoric pronouns; temporal devices; mental state expression; length (3 measures: number of words, number of episodes; number of boy/dog episodes). They asked the participants to tell a story based on a picture book. The two groups differed neither in linguistic abilities, nor in their abilities to comprehend and extract the plot. But the patient group produced less cohesive narratives than the control group: they used fewer pronominal expressions and more full noun phrases, and fewer temporal expressions than the control group. Though the two groups did not differ in the number of mental state expressions they produced, the autistic group did not produce elaboration or explanation regarding the mental states of the characters. Thus, though their linguistic abilities did not set them apart from the control group, the autistic patients' pragmatic abilities did not follow suit.

\subsection{Summary}


To sum up, though there is no doubt that ASD patients are impaired in pragmatic processes in everyday conversation, this may be less obvious in experimental setups that limit the demands made on them. Their pragmatic deficits are clearly related to deficits in theory of mind.

\section{Conclusion}

ASD patients are impaired in social cognition and communication. Autistic patients differ from Asperger patients in that the first are more impaired in language in infancy, being either strongly delayed in language acquisition or failing to acquire language at all. However, in adulthood, high- functioning autistic and Asperger patients seem to level out in terms of linguistic abilities, at least as far as the lexicon is concerned, members from both groups, however, often remaining far below the lexical level of typically developing adults.

Additionally, ASD patients are notable for pragmatic difficulties which seem partly independent of the linguistic level they may attain: in other words, even in those patients who are verbal and high functioning, difficulties in pragmatic utterance interpretation as well as in discourse management remain very prominent and are a source of major communicative difficulties, though this is more obvious in natural conversations than in experimental setups.

Though it might seem that both the difficulties in acquiring language during childhood and the pragmatic deficits in adulthood stem from the same underlying cognitive deficit, it is not clear that this is the case, and, indeed, it seems that the pragmatic deficits in adulthood may be more directly related to deficits in theory of mind, while the acquisition difficulties in childhood may be more directly related to more primitive social difficulties, which may persist in adulthood without directly impacting or explaining the pragmatic difficulties themselves.

This, however, should not be taken to mean that there are no relations between the social deficits and theory of mind impairments in ASD disorders. As pointed out by Povinelli 
and Vonk (2004), there can be no theory of mind without the lesser ability to "read behaviour", i.e., to identify others' actions. If this ability is deficient in autism (as seems evidenced both by the attentional deficits data in Ceponiene et al. 2003 and by the Cattaneo et al. 2007 study of mirror neurons in autistic children), then it may be the case that theory of mind fails to develop because of insufficient or faulty inputs from that less complex behaviour reading ability. Thus, though the two abilities, theory of the mind on the one hand, and social deficits in behaviour reading on the other, are different and indeed differently impact language at different periods in time, they might nevertheless be related in that the first depends on the second for its normal development. And both have a role to play in sociopragmatic cognition and in the development of linguistic communication.

\section{Notes}

${ }^{1}$ It seems that in the next version of DSM (Diagnostic and Statistical Manual), the distinction between the two pathologies will disappear. Be that as it may, the differences in language acquisition among autism spectrum patients legitimate talk of two groups in the present paper. ${ }^{2}$ There is an ongoing debate (see, e.g., Nassar et al. 2009; King and Bearman 2009) on whether the increase in prevalence merely reflects more frequent diagnoses (including milder cases) or a true increase in the occurrence of the pathology. This will not concern us here.

${ }^{3}$ Restricting the ASD to the best characterized pathologies, that is autism and Asperger Syndrome.

${ }^{4}$ The ages given are means.

${ }^{5}$ The study was financed by Fondation de France, grant $\mathrm{n}^{\circ} 2005010231$.

${ }^{6} \mathrm{We}$ want to express our gratitude to the autistic children who took part in the study, their parents and the staff at the Hospital Saint-Jean de Dieu.

${ }^{7}$ Mean Length of Utterance or MLU - calculated as mean number of words, rather than morphemes per utterance - is a rough but standard measure of linguistic acquisition in children both with and without language impairments (see Leonard 2000).

${ }^{8}$ Given the ratio of boys to girls in autistic children (around four boys for one girl), we will refer to autistic children in general by the masculine pronoun.

${ }^{9}$ The comparatively high prevalence of girls in the cohort ( 1 girl for 2 boys) relative to the general prevalence of girls among autistic children ( 1 girl for 4 boys) is a pure matter of chance.

${ }^{10}$ For comparison, we used the French corpora of normally developing children available on CHILDES, matching autistic and typically developing children on the basis of their MLU in the first session recorded in the corpora.

${ }^{11}$ The reader should remember that the corpora described here are in French. The distribution of words in syntactic categories is language dependent, and different standard distributions would prevail in other languages. 
${ }^{12}$ Indeed, the lexicon seems to remain significantly poorer in adult high- functioning autistic and Asperger patients than in typically developing subjects (see Howlin 2003).

${ }^{13}$ One could debate whether shared intentionality is not as fundamental (see the discussion below).

${ }^{14}$ Williams' Syndrome has been said to be the reverse of autism as far as social abilities are concerned, Williams children being described as extremely social, chatty and friendly. For a less enthusiastic view, see Tager-Flusberg and Sullivan (2000), who, however, addressed the rather cognitively demanding false belief task (see below 4.3) in Williams' Syndrome.

${ }^{15}$ This is directly linked to the linguistic acquisition delay in autism: when parents of an autistic child note that he has not begun talking (or has regressed in his acquisition) by the age of 3 , they usually have the child tested for possible disabilities. Though language delay is not the only reason for medical consultation by parents of autistic children, it does account for a fair number of diagnoses. Given that Asperger children, though delayed, are well in the normal range of age for linguistic acquisition, this usual incentive for seekingmedical help does not exist. As a result, Asperger children are usually diagnosed much later (often by adolescence if not later) (see, e.g., Atwood 1998).

${ }^{16}$ The hypothesis of a critical period during which linguistic acquisition (notably syntax and phonology) can develop naturally and after which language can only be learned through more or less explicit processes such as those used to teach second languages in adolescence and adulthood in typically developing individuals is widely shared, and not restricted to the generative perspective on linguistic acquisition.

${ }^{17}$ Specific and restricted interests are an important diagnostic criterion for all ASD (see above 2.2). They may include train time tables, calendars, highly specialised collections, etc.

${ }^{18}$ It should be noted that young typically developing children may manifest some of the difficulties evidenced by autistic children, though these usually are much milder and less widespread, being more limited to figurative utterances and idioms.

${ }^{19}$ As many standardised tests, including the classical WISC for IQ, the ADOS is divided in different domains, yielding both scores for those different domains and a general score indicating the severity of the pathology.

\section{References}

Aslin, Richard N., Jenny R. Saffran and Elissa L. Newport 1998 Computation of conditional probability statistics by 8-month-old children. Psychological Science 9 (4): 321-324.

Asperger, Hans 1944 Die “autistischen Psychopathen” in Kindesalter. Archiv für Psychiatrie und Nervenkrankheiten 117: 76-136.

Atwood, Tony 1998 Asperger Syndrome: A Guide for Parents and Professionals. New York/Philadelphia: Jessica Kingsley Publishers.

Austin, Peter 1962 How to Do Things with Words. Oxford: Oxford University Press. 
Baron-Cohen, Simon 1995 Mindblindness: An Essay on Autism and Theory of Mind. Cambridge, MA.: The MIT Press.

Baron-Cohen, Simon, Alan Leslie and Uta Frith 1985 Does the autistic child have a theory of mind? Cognition 21: 37-46.

Bates, Elisabeth, Luigia Camaioni and Veronica Volterra 1975 The acquisition of performatives prior to speech. Merrill-Palmer Quarterly 21: 205-224.

Bloom, Paul 2000 How Children Acquire the Meaning of Words. Cambridge, MA: The MIT Press.

Bryson, Susan E., Lonnie Zwaigenbaum, Jessica Brian, Wendy Roberts, Peter Szatmari, Vicki Rombough and Catherine McDermott 2007 A prospective case series of high-risk infants who developed autism. Journal of Autism and Developmental Disorders 37: 12-24.

Carruthers, Peters and Peter K. Smith 1996 Theories of Theories of Mind. Cambridge: Cambridge University Press.

Cattaneo, Luigi, Maddalena Fabbri-Destro, Sonia Boria, Cinzia Pieraccini, Annalisa Monti, Giuseppe Cossu and Giacomo Rizzolatti 2007 Impairment of action chains in autism and its possible role in intention understanding. PNAS 104: 17825-17830.

Ceponiene, Rita, Tuulia Lepistö, Anna Shestakova, Raija Vanhala, Paavo Alku, Risto Näätänen and Kuniko Yaguchi 2003 Speech-sound-selective auditory impairment in children with autism: they can perceive but do not attend. PNAS 100 (9): 5567-5572.

Chevallier, Coralie, Deirdre Wilson, Francesca Happé and Ira Noveck 2010 Scalar inferences in autism spectrum disorders. Journal of Autism and Developmental Disorders 40:1104-1117.

Colle, Livia, Simon Baron-Cohen, Sally Wheelwright and Heather van der Lely 2008

Narrative discourse in adults with high-functioning autism or Asperger syndrome. Journal of Autism and Developmental Disorders 38: 28-40. 
Davies, Martin and Tony Stone 1995a Mental Simulation: Evaluations and Applications. Oxford: Basil Blackwell.

Davies, Martin and Tony Stone 1995b Folk psychology: the Theory of Mind Debate. Oxford: Basil Blackwell.

Dennett, Daniel 1978 Beliefs about beliefs. Behavioral and Brain Sciences 4: 568570.

Durleman, Stephanie and Sandrine Zufferey $\quad 2009$ The nature of syntactic impairment in autism. Rivista di Grammatica Generativa 34: 57-86.

Eales, Martin 1993 Pragmatic impairments in adults with childhood diagnoses of autism or developmental receptive language disorder. Journal of Autism and Developmental Disorders 23: 593-617.

Eilan, Naomi, Christopher Hoerl, Theresa McCormack and Johannes Roessler 2005 Joint attention: Communication and other minds: Issues in Philosophy and Psychology. Oxford: Oxford University Press.

Emerich, David, Nancy Creaghead, Sandra Grether, Donna Murray and Carol Grasha 2003 The comprehension of humorous materials by adolescents with highfunctioning autism and Asperger's syndrome. Journal of Autism and Developmental Disorders 33: 253-257.

Fodor, Jerry 1992 A theory of the child's theory of mind. Cognition 44 (3): 283-296.

Foudon, Nadège 2008 L'acquisition du langage par les enfants autistes: une étude longitudinale. Ph.D. Thesis, Doctoral school of Cognitive Sciences, Université LumièreLyon2.

Frith, Uta 1990 Autism: Explaining the Enigma. Oxford: Oxford University Press.

Frith, Uta (ed.) 1991 Autism and Asperger Syndrome. Cambridge: Cambridge University Press. 
Gallese, Vittorio and Alvin Goldman

1998 Mirror neurons and the simulation theory of mindreading. Trends in Cognitive Sciences 2: 493-501.

Gastbeg, Holly Zajac 1999 Do Individuals with Autism Process Categories Differently? The Role of Typicality. B.S. in Neurosciences and Psychology, Allegheny College.

Goldman, Alvin 2006 Simulating Minds: the Philosophy, Psychology, and Neuroscience of Mindreading. Oxford: Oxford University Press.

Gopnik, Alison and Andrew N. Meltzoff 1993 Words, Thoughts and Theories. Cambridge, MA.: The MIT Press.

Grandin, Temple 1995 Thinking in Pictures and other Reports from my Life with Autism. New York: Doubleday.

Grice, Paul 1989 Studies in the Ways of Words. Cambridge, MA.: Harvard University Press.

Hale, Courtney M. and Helen Tager-Flusberg 2005 Brief report: the relationship between discourse deficits and autism symptomatology. Journal of Autism and Developmental Disorders 35 (4): 519-524.

Happé, Francesca 1993 Communicative competence and theory of mind in autism: A test of relevance theory. Cognition 48 (2): 101-119.

Hirsh-Pasek, Kathryn and Roberta Michnick Golinkoff 1996 The Origins of Grammar: Evidence from Early Language Comprehension. Cambridge, MA.: The MIT Press.

Hirsh-Pasek, Kathryn and Roberta Michnick Golinkoff 2006 Action Meets Words: How Children Learn Verbs. Oxford: Oxford University Press.

Howlin, Patricia 2003 Outcome in high-functioning adults with autism with and without early language delays: implications for the differentiation between autism and Asperger syndrome. Journal of Autism and Developmental Disorders 33: 3-13. 
Jacob, Pierre and Marc Jeannerod 2005 The motor theory of social cognition: a critique. Trends in Cognitive Sciences 9: 21-25.

Kanner, Leo 1947 Autistic disturbances of affective contact. The Nervous Child 2: 217250.

Karmiloff-Smith, Annette, Julia Grant, Ioanna Berthoud, Mark Davies, Patricia Howlin and Orlee Udwin 1997 Language and Williams Syndrome: How intact is "intact"? Child Development 68 (2): 246-262.

King, Marissa and Peter Bearman 2009 Diagnostic change and the increased prevalence of autism. International Journal of Epidemiology [Advanced publication, Sept. 2009]: 1-11. Kjelgaard, Margaret M. and Helen Tager-Flusberg 2001 An investigation of language impairment in autism: Implications for genetic subgroups. Language and Cognitive Processes 16 (2-3): 287-308.

Klin, Ami 1991 Young autistic children's listening preferences in regard to speech: A possible characterization of the symptom of social withdrawal. Journal of Autism and Developmental Disorders 21 (1): 29-42.

Kogan, Michael D., Stephen J. Blumberg, Laura A. Schieve, Coleen A. Boyle, James M. Perrin, Reem M. Ghandour, Gopal K. Singh, Bonnie B. Strickland, Edwin Trevathan and Peter C. van Dyck 2009 Prevalence of parent-reported diagnosis of autism spectrum disorder among children in the US, 2007. Pediatrics 124 (4) 1-9.

Leekam, Sue, Simon Baron-Cohen, Daniel Perrett, Maarten Milders and Susan Brown 1993 Eye-direction detection. A dissociation between geometric and joint-attention skills in autism. Unpublished manuscript, Institute of Social Psychology, University of Kent. Leonard, Laurence B. 2000 Children with Specific Language Impairment. Cambridge, MA: The MIT Press. 
Loukusa, Soile, Eeva Leinonen, Sanna Kuusilo, Katja Jussila, Marja-Leena Mattila, Nuala Ryder, Hanna Ebeling and Irma Moilanen 2007 Use of context in pragmatic language by children with Asperger syndrome or high-functioning autism. Journal of Autism and Developmental Disorders 37: 1049-1059.

Moore, Chris and Philip J. Dunham (eds.) 1995 Joint Attention: Its Origins and Role in Development. Hillsdale, NJ: Lawrence Erlbaum.

Musolino, Julien, Gitana Chunyo and Barbara Landau in press $\quad$ Uncovering knowledge of core syntactic and semantic principles in individuals with Williams Syndrome. Language Learning and Development 6: 126-161.

Nassar, Natasha, Glenys Dixon, Jeny Bourke, Carol Bower, Emma Glasson, Nick de Klerk and Helene Leonard 2009 Autism spectrum disorders in young children: effects of changes in diagnostic practices. International Journal of Epidemiology [Advanced publication, Sept. 2009]: 1-10.

Norbury, Courtenay Frazier 2005 Barking up the wrong tree? Lexical ambiguity resolution in children with language impairments and autistic spectrum disorders. Journal of Experimental Child Psychology 90: 142-171.

Pexman, Penny, Kristin Rostad, Carly McMorris, Emma Climie, Jacqueline Stowkowy and Melanie Glenwright 2011 Processing of ironic language in children with high-functioning autism spectrum disorder. Journal of Autism and Developmental Disorders 41: 1097-1112.

Piatelli-Palmarini, Massimo 1979 Théorie du Langage, Théorie de l'Apprentissage: le Débat entre Piaget et Chomsky. Paris: Le Seuil.

Pijnacker, Judith, Peter Hagoort, Jan Buitelaar, Jan-Pieter Teunisse and Bart Geurts 2009 Pragmatic inferences in high-functioning adults with autism and Asperger syndrome. Journal of Autism and Developmental Disorders 39: 607-618. 
Povinelli, Daniel and Jennifer Vonk

2004 We don't need a microscope to explore the chimpanzee's mind. Mind and Language 19 (1): 1-28.

Premack, David and Guy Woodruff 1978 Does the chimpanzee have a theory of mind? Behavioral and Brain Sciences 4: 515-526.

Pylyshyn,Zenon 1984 Computation and Cognition: Toward a Foundation for Cognitive Science. Cambridge, MA: The MIT Press.

Rapin, Isabelle and Michelle Dunn 1997 Language disorders in children with autism. Seminars in Pediatric Neurology 4 (2): 86-92.

Reznik, J. Steven, Grace T. Baranek, Shaye Reavis, Linda R. Watson, Elizabeth R. Crais, 2007 A parent-report instrument to identify one-year-olds at risk for an eventual diagnosis of autism: The first year inventory. Journal of Autism and Developmental Disorders 37: 1691-1710.

Rizzolatti, Giacomo and Corrado Sinigaglia 2007 Mirrors in the Brain: How our Minds Share Actions and Emotions. Oxford: Oxford University Press.

Saffran, Jenny R., Richard N. Aslin and Elissa L. Newport 1996 Statistical learning by 8month-old infants. Science 274: 1926-1928.

Saffran, Jenny R., Elissa L. Newport and Richard N. Aslin 1996 Word segmentation: the role of distributional cues. Journal of Memory and Language 35: 606-621.

Schuler, Adriana L. and Barry M. Prizant 1985 Echolalia. In: Eric Schopler and Gary B. Mesibov (eds.), Communication problems in autism, 163-184. New York/London: Plenum Press.

Scott, Fiona J., Simon Baron-Cohen, Patrick Bolton and Carol Brayne 2002 Brief report: prevalence of autism spectrum conditions in children aged 5-11 years in Cambridgeshire, UK. Autism 6 (3): 231-237. 
Searle, John R. 1969 Speech Acts: an Essay in the Philosophy of Language. Cambridge: Cambridge University Press.

Sigman, Marian and Connie Kasari 1995 Joint attention across contexts in normal and autistic children. In: Chris Moore and Philip J. Dunham (eds.), Joint Attention: Its Origins and Role in Development, 189-204. Hillsdale, NJ: Lawrence Erlbaum.

Soulières, Isabelle, Laurent Mottron, Daniel Saumier and Serge Larochelle 2006

Atypical categorical perception in autism: autonomy of discrimination. Journal of Autism and Developmental Disorders 37: 481-490.

Sperber, Dan and Deirdre Wilson 1995 Relevance: Communication and Cognition. Oxford: Basil Blackwell. First published Oxford: Basil Blackwell [1986].

Surian, Luca, Simon Baron-Cohen and Heather Van der Lely 1996 Are children with autism deaf to Gricean maxims? Cognitive Neuropsychiatry 1: 55-71.

Tager-Flusberg, Helen and Judith Cooper 1999 Present and future possibilities for defining a phenotype for specific language impairment. Journal of Speech, Language, and Hearing Research 42: 1001-1004.

Tager-Flusberg, Helen and Kate Sullivan 2000 A componential view of theory of mind: evidence from Williams syndrome. Cognition 76: 59-89.

Tager-Flusberg, Helen, Susan Calkins, Tina Nolin, Therese Baumberger, Marcia Anderson and Ann Chadwick-Dias 1990 A longitudinal study of language acquisition in autistic and Down syndrome children. Journal of Autism and Developmental Disorders 20 (1): 1-21. Tomasello, Michael 2005 Constructing a Language: a usage-based Theory of Language Acquisition. Cambridge, MA.: Harvard University Press.

Tomasello, Michael 2008 Origins of human communication. Cambridge, MA.: The MIT Press. 
Tomasello, Michael, Melinda Carpenter, Josep Call, Tanya Behne and Henrike Moll 2005 Understanding and sharing intentions: The origins of cultural cognition. Behavioral and Brain Sciences 28: 675-735.

Wellman, Henry M., David Cross and Julanne Watson 2001 Meta-analysis of theory-ofmind development: the truth about false belief. Child Development 72: 655-684.

Williams, Donna 1992 Nobody Nowhere. London: Doubleday.

Wimmer, Heinz and Joseph Perner 1983 Beliefs about beliefs: representation and constraining function of wrong belief in young children's understanding of deception. Cognition 13: 103-128.

Winkler, Isvan, Helena Kushnerenko, Janos Horvath, Rita Ceponiene, Vineta Fellman, Minna Huotilainen, Risto Näätanen and Elyse Sussman 2003 Newborn infants can organize the auditory world. PNAS 100: 11812-11815. 